\title{
Personal and ethical components of the engineer in the 21st century
}

\author{
V.P. Potamskaya ${ }^{1, *}$, E.A. Evstifeeva ${ }^{2}$, S.I. Filippchenkova ${ }^{3}$ \\ ${ }^{1}$ Candidate of Philosophy, Tver state technical university, 22 A. Nikitin quay, 170026, Tver, Russia \\ ${ }^{2}$ Doctor of Philosophy, Tver state technical university, 22 A. Nikitin quay, 170026, Tver, Russia \\ ${ }^{3}$ Doctor of Psychology, Tver state technical university, 22 A. Nikitin quay, 170026, Tver, Russia
}

\begin{abstract}
The article studies personal components of a modern engineer who is a key figure in the Russian and global space. The vector of thinking, ethical priorities, reflective positions and identities determine the way to find a techno-humanitarian balance as a condition for the survival and prospects of mankind. A significant influence on the formation of engineer's identities is exerted by historical and cultural traditions. Engineering culture has a connective structure that forms a single space of experience and activity. Memory and continuity are interrelated; identities can belong to any scientific school existing in the educational institution, field of knowledge, or to the Russian engineering school as a whole. The authors indicate that key concepts of identities of a modern engineer are responsibility, ethical reflection and social assessment of technology. Modern engineering ethics is reflected in ethical codes which reveal the ethical space and responsibilities of the engineer and impose responsibility for all processes taking place in a technogenic society. The practical-design approach is based on the tools of the post-non-classical methodology: key components of the engineer's personal potential are correlated with the university self-developing environment, reflective activities at the undergraduate and graduate levels, and further engineering practice. The study on the personal potential and identities can be used to justify the need to expand the sociohumanitarian paradigm in engineering education, develop the concept "personal potential", and identify features of engineer's identity formation. The development of a model for training engineers using sociohumanitarian reflective methods converging personal and professional competencies and ethical priorities meets the role of engineering education, tasks of ensuring the competitiveness of Russian industry.
\end{abstract}

\section{Introduction}

Changes caused by technologies, imbalances of technologies, the anthropogenic crisis of the 21 st century, are one of the fundamental problems of modern philosophical reflection. The problems of human survival, harmonization of technical and humanitarian fields of knowledge, development of humanitarian-reflective thinking play a global role. One of the ways to overcome the confrontation between natural-artificial, technicalethical is a dialogue between natural and humanitarian paradigms of scientific knowledge. The solution actualizes the problem of training competitive engineers. The key figure of the XXI century is an engineer. Technological progress stimulates the need for modernization of the Russian engineering education. The choice of a way to find a techno-humanitarian balance both as a condition for the survival and prospects of mankind and a solution to the local problem of the competitiveness of Russian industries depends on the vector of thinking, ethical priorities, reflective positions and identities of future engineers. The personal potential used in socio-humanitarian science implies a possibility of changing personal characteristics of an engineer, commensurability of engineering competencies and challenges of engineering practices (Leontyev, 2011). At the same time, the engineer's personal potential should be considered as an opportunity for self-determination and self-management in the professional and social environment (Evstifeeva et al., 2014)

\section{Problem Statement}

The engineer's personal potential, as well as his identity, is determined by the dialogue of technical, humanitarian and natural sciences, the relationship of professional and socio-humanitarian knowledge and experience. The modern engineer is called upon to meet constant challenges of the rapid transformation of social and technological practices and current trends of the engineering profession. Highly specialized training of an engineer in the "laboratory conditions" is insufficient for adaptability to new types of knowledge, and the anthropogenic factor plays a significant role in the organization of production. As a result, engineer's responsibility for the implementation of new technologies is increasing.

\section{Research Questions}

The rationalization of modern conditions emphasized by M. Weber is determined by the state of real technology.

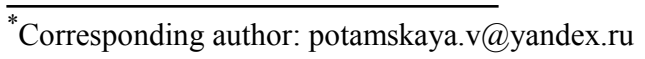


Technological advances require an inevitable reckoning. This technology-related inevitability can be mitigated, but cannot be fundamentally eliminated, since it is based on mandatory organizational functional relationships and the laws of structuring the physical world (Rapp, 1989). The research topic seems relevant due to several factors. Firstly, the personal potential and identities of the modern engineer must comply with requirements of a modern self-developing technogenic information environment. Requirements of modern society include engineering competencies and high humanitarian requirements, value orientations, and professional socialization. Secondly, the need to translate the experimental potential within the framework of existing engineering schools and traditions of Russian science actualizes the problem of professional identity. Thirdly, innovative processes have a significant impact on the formation of the engineer's potential. Fourth, a significant problem is aging of the engineering personnel, as well as the outflow of young specialists abroad. The above factors make it difficult to answer challenges of our time - engineering competitiveness in the field of high technology, reproduction of the qualified engineering personnel, formation of a "knowledge society". Russian science is solving the problem of the shortage of young scientists capable of professional activities in the conditions of a transforming and risky modern society. In turn, complexity of engineering education and formation of an engineering identity make it difficult to answer social and technological challenges of our time, i.e. ensure the competitiveness of an engineering product, reproduction of the engineering personnel, which has a required set of competencies to perform engineering, research, and social functions.

\section{Purpose of the Study}

The article aims to develop a model for training the engineering personnel using socio-humanitarian reflective technology that combines personal and professional competencies and ethical priorities of the engineer. The model meets the role of engineering education, current trends in the development of engineering activities, and tasks of ensuring the global competitiveness of Russian industries.

\section{Research Methods}

The method for training a future engineer should be guided by the basic principles of modern philosophy of science and technology, the principles of post-nonclassical rationality and interdisciplinarity (Stepin, 2003) correlated with the environmental paradigm of humansized self-developing systems (Lepsky, 2015), the ethics of self-developing environments (Lefebvre, 2003). The socio-humanitarian technology used to develop the engineer's personal potential and organize the university self-developing environment is reflective management, a reflexive approach and strategic reflective games. The concept of the engineer's personal potential is a generalized (personal, subjective, cognitive) opportunity for self-change in the professional and social environment. It is based on key concepts and concepts of projective philosophy. The application of the method contributes to the personal potential and professional identity with the help of social humanitarian technologies in the self-developing environment of the university. Responsibility is an ability of a person to reproduce and build himself in personal and social activities, which requires self-control, self-forecasting, and self-designing (an ontological plan). In axiological terms, responsibility is ethical sensitivity to the Other, adopting a social and moral code of dignity. The ethical component of the engineer's professional identity is a relevant professional structure of value priorities.

\section{Findings}

Professional and personal qualities of an engineer, his identity are based on effective technologies, research methods, transfer of professional knowledge to the field of education and engineering practices, as well as relations with historical and cultural traditions. One aspect of such qualities is the engineer's identity. Engineering culture has a connective structure forming a single space of experience and activity (Assman, 2004). Memory and continuity are interrelated, and identities belong to any scientific schools existing in a particular educational institution or field of knowledge. An individual memory is created due to the participation in communication processes and involvement in various social groups. The Russian Engineering School is clearly structured, functionally and methodologically developed. The core of the training was general engineering disciplines, which are the basis for any engineering areas and provide a link between theoretical and practical training. Among the outstanding engineers are I.P. Kulibin, A.Z. Telyakovsky, D.K. Chernov, A.F. Mozhaysky, P.N. Yablochkov, A.K. Nartov, N.I. Lobachevsky, V.Ya. Struve, K.E. Tsiolkovsky, A.N. Krylov, N.E. Zhukovsky, S.I. Mosin, I.M. Gubkin, P.N. Lebedev, I.I. Sikorsky, V.A. Degtyarev, A.N. Tupolev, P.O. Sukhov, S.V. Ilyushin, N.N. Polikarpov et al.

However, in the beginning of the XXI century, an understanding of engineering has changed. If in the XX century, the engineer was considered as an organizer of production, a creator of new equipment and technology, at present engineering activities are largely determined by computer modeling technologies. As a result, engineer's responsibility for the implementation of new technologies is increasing. Technological progress entails new problems and risks. H. Lenk, a vice president of the European Academy of Sciences, summarizes them as follows: an increase in the number of those who received side effects from technical events; increasing destruction of nature under the influence of human activities; deterioration of the biomedical and environmental situation; medical-pharmaceutical risks; a threat of human transformation into a technological object due to the interference with the genetic code (Lenk, 2013).

The sources of reflection on negative consequences of scientific and technical projects are found in the Essays on Philosophy by M. Heidegger, in which the following 
principle is postulated - surprise is replaced by fear which forms a fundamentally different, responsible worldview (Zheleznyak, Seredkina, 2017). According to experts, engineering ethics "turns out to be nothing more than a renaming of the organic part of labor morality inherent in the whole spectrum of professions, and there is no need to talk about special normative and value subsystems" (Vasenkin, 2011). A. Huning offers a different point of view, considering ethics as a principle of responsibility, according to which an engineer is regarded as a "servant of humanity" (Huning, 2010). At the same time, the principles of ethics are considered as ideas of humanism: human development and humanization of technology are declared the highest value.

Currently, the multidisciplinary approach "Responsible Research and Innovation" (RRI) is dominant in European studies. Identity of a Western engineer is formed on its basis. Its key concepts are responsibility, ethical reflection and social assessment of technology (Zheleznyak, Seredkina, 2017). Thus, universal ethics implies responsibility. Courses on ethical issues of engineering are taught at Massachusetts Institute of Technology, Stanford University, California Institute of Technology and other leading universities in the United States and Europe, as an integral part of engineering training. One of the most important criteria of the American Council for the evaluation of educational engineering programs is "Personal responsibility and adherence to professional ethics in integrated (applied, innovative) engineering activities" (Gasheva, 2014).

Engineering ethics acts as a link between the technical community and society. G. Jonas (Jonas, 2004), H. Lenk (Lenk, 1989), G. Ropol (Ropol, 1989), and A. Huning (Huning, 2010) believe that existing ethical concepts are not able to solve the problems of technological development, since the traditional way of life was destroyed due to the inconsistency with globalization processes and the reorientation of society towards mass consumption. Therefore, it is necessary to develop a new ethical theory that would correspond to modern information processes. The new ethical theory must take into account all the long-term consequences of technical activities and be based on responsibility. The ontological responsibility program by $G$. Jonas is best known. Responsibility is likened to the Kantian categorical imperative. According to E. Agazzi, the main moral criterion in assessing judgments about technology is value optimization (Agazzi, 1998).

Modern engineering ethics is reflected in ethical codes. One example is the Engineering Code of Ethics developed by the National Association of Professional Engineers of the United States. The preamble of the code states that engineers must follow high standards of integrity due to the impact of modern engineering on life quality. Consequently, engineers should be honest, impartial, fair, protect public health, safety and wellbeing.

Fundamental qualities are formulated in the following statements: engineers are required to give priority to safety, health and well-being of the population; provide services in the field of their competence; be objective and truthful; avoid fraudulent actions, falsifications and financial fraud; be honest, responsible, ethical in order to preserve reputation and usefulness of their profession. The principles of engineering ethics are specified, and an extensive part of the code is devoted to professional obligations of an engineer (NSPE Code of Ethics for Engineers, 2018).

In Russia, the APEC Engineer's Code of Professional Ethics is most known for defining basic moral principles and standards of engineering creative activities. The Russian code is distinguished by wider formulations and less emphasis on financial aspects and falsifications. The basic values of the professional ethics are based on fairness, courtesy, a conscientious attitude towards customers and employees, confidentiality, moral encouragement of colleagues, publication of practical results, an impartial attitude towards people, regardless of their race, religious beliefs, age, mental abilities, marital, marital status and national origin. Other fundamental requirements are collectivism, which is unusual for the American model, the values of professional and universal communication, reasonable freedom of exchange of scientific and technical information, the search and support of young talented specialists, humanity, integrity, perseverance, continuous professional development, active enlightenment, struggle with ignorance, incompetence, technophobia (APEC Engineer Code of Professional Ethics, 2011).

The American and Russian codes reveal the ethical space and responsibilities of the engineer, impose responsibility for all the processes taking place in a technogenic society. However, it seems that the engineer should focus mainly on role responsibility, which implies certain forms of responsibility and research tasks.

\section{Conclusion}

Engineering activities are constantly changing. Therefore, required qualities of an engineer are cognitive flexibility, a high degree of adaptability, attention to ethical aspects. The education process must meet two goals: orientation of the learning process to the extremely broad development of the person and formation of his personal qualities, and disclosure of individual opportunities for the constant professional search and self-improvement. The engineer should focus on professional competencies and assimilate educational, cultural and ethical elements that contribute to various innovations. In our research, the tools of the post-non-classical methodology have been tested for the first time, the key components of the engineer's personal potential have been correlated with the university self-developing environment, reflective activities of undergraduate and graduate students, and engineering activities. The study of the personal potential and identities can be used to justify the need to expand the socio-humanitarian paradigm in engineering education, develop the concept of personal potential and ethics, identify features of the axiological component and engineer's identity. The new model of engineer's identity formation implies a scientifically-applied result - the development of a model of the university self-developing environment, in which the subjects of engineering training 
are rethought and research achievements are introduced into the educational space and engineering practice in order to develop personal and professional resources of engineering thinking.

\section{References}

1. NSPE Code of Ethics for Engineers (2018) Retrieved from: https://www.nspe.org/resources/ethics/codeethics

2. E. Agazzi, The Moral Dimension of Science and Technology. (Moscow, Moscow Philosophical Foundation. 1998)

3. Ya. Assman, Cultural memory: Writing, memory of the past and political identity in the high cultures of antiquity. (Moscow, Languages of Slavic Culture 2004)

4. A.V. Vasyonkin. Engineering ethics: on the way to a new worldview. Retrieved from: https:/cyberleninka.ru/article/n/inzhenernaya-etikana-puti-k-novomu-mirovozzreniyu (2011)

5. Yu.V. Gasheva, (2014) Higher Education in Russia, Engineering Ethics: Problems of Formation and Assessment of Competence. 6. 85-93.

6. E.A. Evstifeeva, S.V. Rassadin, S.I. Filippchenkova, S.V Ivanov, 21st Century Engineer: Convergence of Personal, Professional, and Social Competencies in a Decision Making Situation. Power, 9, 32-36. (2014)

7. V.N. Zheleznyak, E.V.Seredkina, Bulletin of PNIPU. Culture. Story. Philosophy. Law, Engineering Ethics in a Technical University: Difficulties and Hopes, 2. 33-40 (2017)
8. G. Jonas, The principle of responsibility. Ethical experience for technological civilization. (Moscow, Iris-Press. 2004)

9. APEC Engineer Code of Ethics Retrieved from: http://portal.tpu.ru/apec/certification/requirement/cod e (2011).

10. H. Lenk, Philosophy of Technology in Germany. Responsibility in technology, for technology, using technology. 372-392. (Moscow, Progress. 1989)

11. H. Lenk, Reflections on modern technology. Retrieved from: https:/gtmarket.ru/laboratory/basis/6037/6048 (2013)

12. D.A. Leontyev, Personal Potential: Structure and Diagnostics. (Moscow, Smysl, 2011).

13. Lepsky, V.E. Reflective processes and management. Collection of materials of the International Symposium. From a monodisciplinary to a transdisciplinary approach to the development of scientific knowledge (management issues) 7-14 (Moscow: Kogito-Center. 2015).

14. V.A. Lefevre, Reflection. (Moscow, Kogito-Center, 2003).

15. F. Rapp, Philosophy of technology in Germany. Prospects for philosophy of technology. 75-89, (Moscow: Progress, 1989)

16. G. Ropol, Philosophy of technology in Germany. Is technology a philosophical problem. 191-202. (Moscow, Progress, 1989)

17. V.S. Stepin, Theoretical knowledge. (Moscow, Progress-Tradition, 2003).

18. A. Huning, Engineering activities in terms of ethical and social responsibility. Retrieved from: https:/gtmarket.ru/laboratory/expertize/3132/3141 (2010) 